\title{
Thermal Load Reduction System Development in a Hyundai Sonata PHEV
}

\section{Cory J. Kreutzer, John Rugh, and Jeff Tomerlin}

National Renewable Energy Laboratory

CITATION: Kreutzer, C., Rugh, J., and Tomerlin, J., "Thermal Load Reduction System Development in a Hyundai Sonata PHEV," SAE Technical Paper 2017-01-0186, 2017, doi:10.4271/2017-01-0186.

Copyright (C) 2017 SAE International

\begin{abstract}
Increased market penetration of electric drive vehicles (EDVs) requires overcoming a number of hurdles, including limited vehicle range and the elevated cost in comparison to conventional vehicles. Climate control loads have a significant impact on range, cutting it by over $50 \%$ in both cooling and heating conditions. To minimize the impact of climate control on EDV range, the National Renewable Energy Laboratory has partnered with Hyundai America and key industry partners to quantify the performance of thermal load reduction technologies on a Hyundai Sonata plug-in hybrid electric vehicle. Technologies that impact vehicle cabin heating in cold weather conditions and cabin cooling in warm weather conditions were evaluated. Tests included thermal transient and steady-state periods for all technologies, including the development of a new test methodology to evaluate the performance of occupant thermal conditioning. Heated surfaces demonstrated significant reductions in energy use from steady-state heating, including a 29\%-59\% reduction from heated surfaces. Solar control glass packages demonstrated significant reductions in energy use for both transient and steady-state cooling, with up to a $42 \%$ reduction in transient and $12.8 \%$ reduction in steady-state energy use for the packages evaluated. Technologies that demonstrated significant climate control load reduction were selected for incorporation into a complete thermal load reduction package. The complete package is set to be evaluated in the second phase of the ongoing project.
\end{abstract}

\section{Introduction}

Operation of the climate control system has been shown to significantly degrade the range of electric drive vehicles (EDVs) due to the need to power the air conditioning $(\mathrm{A} / \mathrm{C})$ and heating system. As an example, a Ford Focus Electric vehicle tested at Argonne National Laboratory's Advanced Powertrain Research Facility measured degradation in vehicle range of $53.7 \%$ due to operation of the $\mathrm{A} / \mathrm{C}$ system and a $59.3 \%$ degradation in range due to operation of the cabin heating system [1]. By minimizing the energy needed for vehicle climate control, more energy is available for propulsion, thereby increasing the range of the vehicle.
Climate control energy use is determined by the efficiency of the heating, ventilating, and air conditioning (HVAC) components, the effectiveness of thermal energy delivery to key body segments of the occupant, control strategy, and the thermal energy exchange between the surroundings and the occupied space. Placing emphasis on thermal load reduction for plug-in hybrid electric vehicles (PHEVs) and electric vehicles is expected to lead to battery sizing and cost reductions, reduced climate control equipment capacities, as well as enabling advanced HVAC system components and control strategies. In addition, thermal load reduction and advanced climate control design can positively impact occupant comfort. A key metric in the performance of a thermal load reduction strategy is the overall thermal state of the occupant. By incorporating a scale for occupant thermal state characterization such as that developed by Zhang [2] ], a better understanding of the true performance of a technology can be obtained.

The quantification of a number of individual thermal load reduction strategies has been performed for both heating and cooling at the proof-of-concept level. For instance, an infrared reflective windshield combined with pre-ventilation demonstrated on a pre-production electric vehicle reduced the transient 20-minute A/C cool-down energy consumption in summer conditions by $44.2 \%$ [ $[3]$. Similarly, a combination of driver-only panel air ventilation in combination with heated seating, steering wheel, and floor mat demonstrated on the pre-production electric vehicle reduced the 20-minute transient heating energy consumption in winter conditions by $28.5 \%$ [ 4 ]. Finally, the potential impact of solar reflective coatings measured by applying a solar-reflective film on the roof of a light-duty vehicle during summer daytime conditions, obtaining a $6.7^{\circ} \mathrm{C}$ reduction in exterior surface temperature of the vehicle roof, demonstrating its ability to positively impact vehicle thermal performance [5].

While the impact of thermal load reduction strategies has been demonstrated under various conditions, their performance is dependent on manufacturing constraints, and the need remains to quantify individual technologies at a production-ready stage rather than the proof-of-concept stage. In addition, it is expected that the 
performance of some thermal load reduction technologies is dependent on one another. Therefore, a need exists to implement and quantify an entire thermal load reduction system as a whole

The National Renewable Energy Laboratory (NREL), in partnership with Hyundai America Technical Center, Inc. (HATCI), Pittsburgh Glass Works (PGW), PPG Industries, Hanon Systems, Sekisui S-LEC America, and Gentherm, is focusing on development and integration of a complete thermal load reduction system for a light-duty electric vehicle. The goal of the project is to increase grid-connected EDV range by $20 \%$ at peak heating and cooling conditions over the combined city/highway drive cycle. The objective is expected to be met by decreasing thermal loads during all modes of vehicle operation, including thermal soak, cool-down and warm-up transients, steady-state operation, and thermal preconditioning while connected to the grid. The project duration is three years, divided into an individual technology development and assessment phase (Phase I) followed by a technology integration and performance evaluation phase (Phase II). This report focuses on the development and assessment of the candidate thermal load reduction technologies.

\section{Approach}

For the project, HATCI provided the Hyundai Sonata PHEV platform and technology interfacing requirements. PGW provided automotive glass manufacturing capabilities for the project in addition to advanced glass technologies for evaluation. Sekisui provided advanced materials and integration expertise for candidate thermal load-reducing glass technologies, collaborating with PGW for manufacturing. PPG Industries developed and provided baseline and solar reflective paint formulations. Gentherm provided actively heated and cooled climate seats, door glass defogging, and individual heated surface technologies.

\section{Description of Phase I Candidate Technologies}

A description of both the cold weather and warm weather Phase I candidate technologies and the corresponding project partner is provided in Figures $1-\underline{5}$. Technologies in red represent candidates for warm weather load reduction while those in blue represent candidates for cold weather load reduction.

\begin{tabular}{|l|c|c|c|}
\hline \multicolumn{4}{|c|}{ Solar Control Glazings: PGW \& Sekisui } \\
\hline & Package A & Package B & Package C \\
\hline Outer Glass & $2.1 \mathrm{~mm}$ Clear & $\begin{array}{c}2.1 \mathrm{~mm} \text { Clear with } \\
\text { PGW Double Silver IR } \\
\text { Reflective Coating }\end{array}$ & $\begin{array}{c}\text { 2.0 mm Ultraclear with } \\
\text { PGW Triple Silver IR } \\
\text { Reflective Coating }\end{array}$ \\
\hline Interlayer & $\begin{array}{c}\text { Sekisui IR Reflecting } \\
\text { \& Absorbing }\end{array}$ & Sekisui IR Absorbing & $\begin{array}{c}0.76 \mathrm{~mm} \text { Polyvinyl } \\
\text { Butyral }\end{array}$ \\
\hline Inner Glass & $2.1 \mathrm{~mm}$ Green & $1.8 \mathrm{~mm}$ Solex & $2.1 \mathrm{~mm}$ Clear \\
& \\
$\begin{array}{l}\text { Laminated solar control } \\
\text { automotive glass for } \\
\text { windshield, front door, and } \\
\text { rear door locations. }\end{array}$ & \\
\hline
\end{tabular}

Figure 1. Candidate solar control glass packages (photo credit: Pittsburgh Glass Works)

\section{Solar Reflective Paint: PPG Industries}

\begin{tabular}{|c|c|}
\hline & Total Solar Reflectivity [\%] \\
\hline Conventional Vehicle Paint & $6.62 \%$ \\
\hline NIR Reflective Vehicle Paint & $38.11 \%$ \\
\hline Difference & $31.49 \%$ \\
\hline
\end{tabular}

Automotive paint with an elevated reflectivity in the near infrared spectrum.

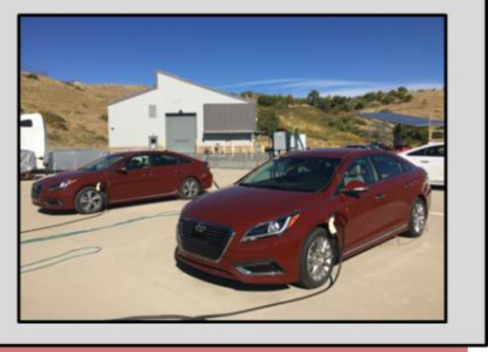

Figure 2. Solar reflective paint candidate technology (photo credit: Cory Kreutzer, NREL)

\section{Ventilated/Cooled Seats: Gentherm}

\begin{tabular}{|c|c|}
\hline Power Requirements & Standard 12VDC System \\
\hline Seat Cooling Levels & High, Medium, Low, Off \\
\hline Test Procedure Used & $\begin{array}{c}\text { Transient and steady-state with } \\
\text { occupant thermal sensation } \\
\text { evaluation }\end{array}$ \\
\hline
\end{tabular}

Modified climate control seat ventilated cushion and back with thermoelectric device enabled cooling.

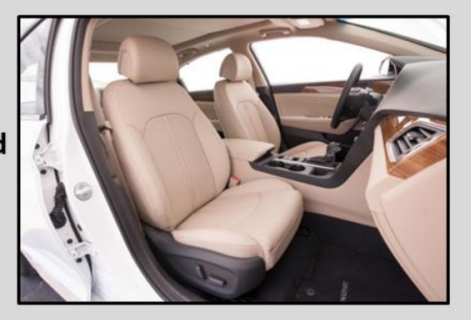

Figure 3. Ventilated/cooled seats candidate technology (photo credit: Gentherm, Inc.)

\section{Heated Surfaces: Gentherm}

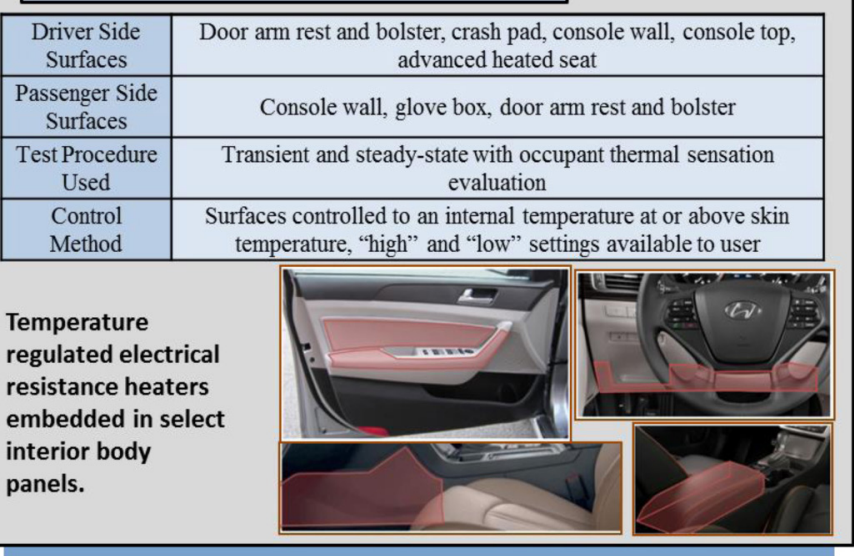

Figure 4. Heated surfaces candidate technology (photo credit: Gentherm, Inc.) 


\begin{tabular}{|c|c|}
\hline Power Requirements, Windshield & $42 \mathrm{VDC}$ \\
\hline Power Requirements, Door Demister & Standard 12VDC System \\
\hline Door Demister Heater Type & PTC Heater \\
\hline Test Procedure Used & Cold Weather Defogging \\
\hline $\begin{array}{l}\text { Electrical resistance heated } \\
\text { windshield (PGW) combined } \\
\text { with PTC heater based } \\
\text { demister and integrated } \\
\text { blower assembly } \\
\text { (Gentherm) }\end{array}$ & \\
\hline
\end{tabular}

Figure 5. Alternative defogging/demisting system candidate technology (photo credit: Pittsburgh Glass Works)

\section{Phase I Experimental Setup}

Two pre-production 2016 Hyundai Sonata PHEVs were provided by HATCI and instrumented at NREL's Vehicle Integration and Testing Facility, as shown in Figure 6. The facility is located in Golden, Colorado, at an elevation of 5,997 feet, latitude $39.7 \mathrm{~N}$, and longitude $105.1 \mathrm{~W}$. The two vehicles were oriented to face south for maximum solar irradiation into the air volume surrounding the driver. The vehicles were separated to minimize shadowing effects. Each vehicle was instrumented with a total of $48 \mathrm{k}$-type thermocouples installed on the exterior glass and opaque surfaces, interior glass and trim surfaces, and front occupant seating, as well as a range of internal air temperature measurements, including driver's breath and footwell locations and HVAC vent outlet locations. Air temperature sensors were equipped with a double concentric cylindrical radiation shield to prevent errors due to direct solar radiation exposure. A National Instruments cDAQ-9188 equipped with multiple NI-9214 thermocouple cards was used for data acquisition. All thermocouples were calibrated using a five-point calibration protocol, achieving a U95 uncertainty of less than $0.11^{\circ} \mathrm{C}$ for each measurement in accordance with American Society of Mechanical Engineers standards [] $]$. For warm weather testing, a Load Controls Universal Power Cell was used to measure traction battery power with an accuracy of $\pm 75 \mathrm{~W}$ and, because the vehicles were kept in electric vehicle mode, only electric power was recorded. For cold weather testing, thermocouples were installed in the coolant flow both upstream and downstream of the heater core. In addition, a Flow Technology turbine flow meter was installed to measure coolant flow rate. The coolant composition was measured by its refractive index. Thermal power entering the vehicle from the heater core was calculated from the flow, temperature differential, and coolant composition data. Finally, the vehicle's positive temperature coefficient (PTC) heater electrical power was recorded - it was assumed that $100 \%$ of its electrical energy was converted into thermal energy going into the vehicle. The heater core and PTC heater powers were combined for cold weather testing data analysis.

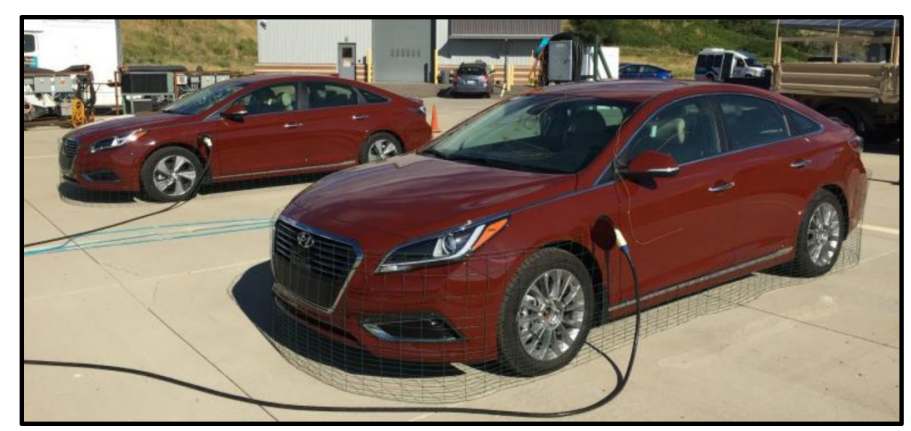

Figure 6. Hyundai Sonata PHEV test vehicles at NREL's Vehicle Testing and Integration Facility (photo credit: Cory Kreutzer, NREL)

\section{Phase I Experimental Test Process}

For all tests, one vehicle was designated as the baseline vehicle, which remained unmodified throughout the duration of the test program. The second vehicle was designated as the modified vehicle, and each candidate technology was installed in the modified vehicle independently from one another, so that their performance was characterized on an individual basis. Prior to evaluating any candidate technology for both summer and winter testing, baseline tests were performed with both vehicles in the unmodified condition. The baseline performance characterization provided a means to calibrate the baseline vehicle to represent an unmodified version of the test vehicle while a technology was evaluated and also for variable weather conditions.

A three-step method was used to experimentally quantify the performance of individual candidate technologies. For both cold and warm weather testing, the three-step method consisted of a vehicle soak period in outdoor conditions, followed by a transient period, and finally a steady-state period. A schematic representation of the test process is provided in Figure 7 for both warm and cold weather testing. For warm weather testing, baseline and modified vehicles were preconditioned by soaking in the morning outdoor environment. Next, the transient cool-down step was performed with maximum $\mathrm{A} / \mathrm{C}$ settings, and the power delivered to the HVAC system was integrated until the cabin mean air temperature attained a target value. Finally, the A/C settings were changed to fully automatic temperature control with a setpoint of $72^{\circ} \mathrm{F}$ and power delivered was once again integrated for a specified time interval. Cold weather testing was similar although testing was started at 3:00 a.m. to remove variations caused by the sun.

The three-step testing methodology was adapted for candidate technologies that more directly targeted occupant climate conditioning rather than the boundary between the vehicle and outdoor environment. For summer testing of these technologies, human occupants were included and provided real-time evaluation of their thermal sensation throughout the test. The preconditioning phase included a 30 -minute occupant precondition in an office environment. The transient cool-down endpoint was determined by the occupant achieving a target thermal sensation rather than a target cabin air temperature. For steady-state cooling, the occupant in the modified vehicle adjusted the cabin air temperature setpoint such that the combined effect of the candidate technology and the modified air temperature provided a body sensation equivalent to that obtained in the baseline vehicle. Analogous adaptations were made for cold weather testing. 

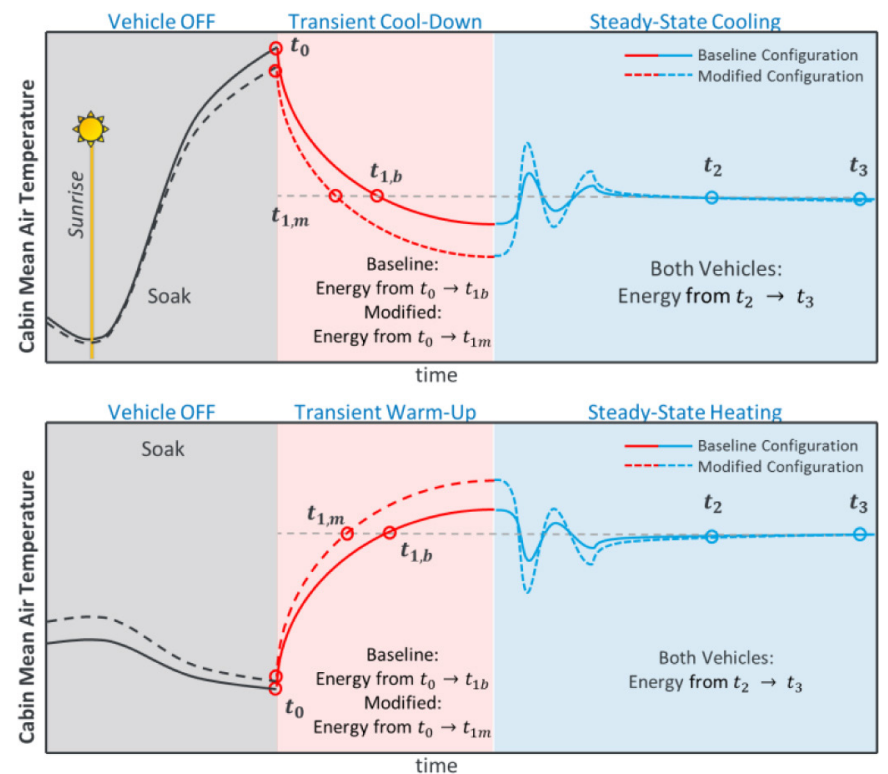

Figure 7. Warm weather (upper) and cold weather (lower) testing methodologies used for Phase I testing of candidate technologies

\section{Cold Weather Defogging Test Description}

For evaluation of the heated windshield and door demister compared to the baseline vehicle, each vehicle was equipped with humidifiers in the vehicle cabin. The defogging test procedure consisted of four parts: preconditioning, transient defogging, steady-state defogging, and steady-state defogging with moderate heating. Electrical power for the heated windshield was measured using a digital power supply, and the door demister power was measured using a voltage reference and current shunt. For preconditioning, the vehicles were soaked in cold weather conditions and the humidifiers were operated for 20 minutes to provide saturated conditions for the vehicle interior. Thereafter, transient defogging was initiated by setting the baseline vehicle to maximum heat and defrost while only the windshield and door demisters were activated for the modified vehicle. Windshield clearing was visually monitored, and the time was recorded when the windshield area was fully cleared as defined by the swept area of the windshield wipers. After both windshields were clear, the test was continued undisturbed to collect steady-state defogging energy use. Because the heated windshield and door demisters do not directly contribute to vehicle interior heating, a final comparison was made by setting the modified vehicle to include moderate heating with medium blower, maximum temperature, and panel and floor ventilation, while the baseline vehicle was kept in defrost mode.

\section{Results}

\section{Summer Technology Evaluations}

Prior to the evaluation of the technologies, baseline testing of the two vehicles was completed to characterize the vehicle-to-vehicle differences and sensitivity to changes in the outdoor environment. Summaries of the baseline transient and steady-state testing are provided in Figures $8 \mathrm{~A}$ and $\underline{8 \mathrm{~B}}$, including the vehicle HVAC settings used for both portions of the test and the correlation between the test and control vehicles. A strong correlation between the vehicles was obtained for both the transient cool-down and steady-state cooling portions of the test, with least-squares coefficients of determination $\left(\mathrm{R}^{2}\right)$ of 0.992 and 0.908 , respectively. Baseline test correlations between vehicles were used to provide a correction factor to the control vehicle to represent an unmodified test vehicle performance during technology evaluations.

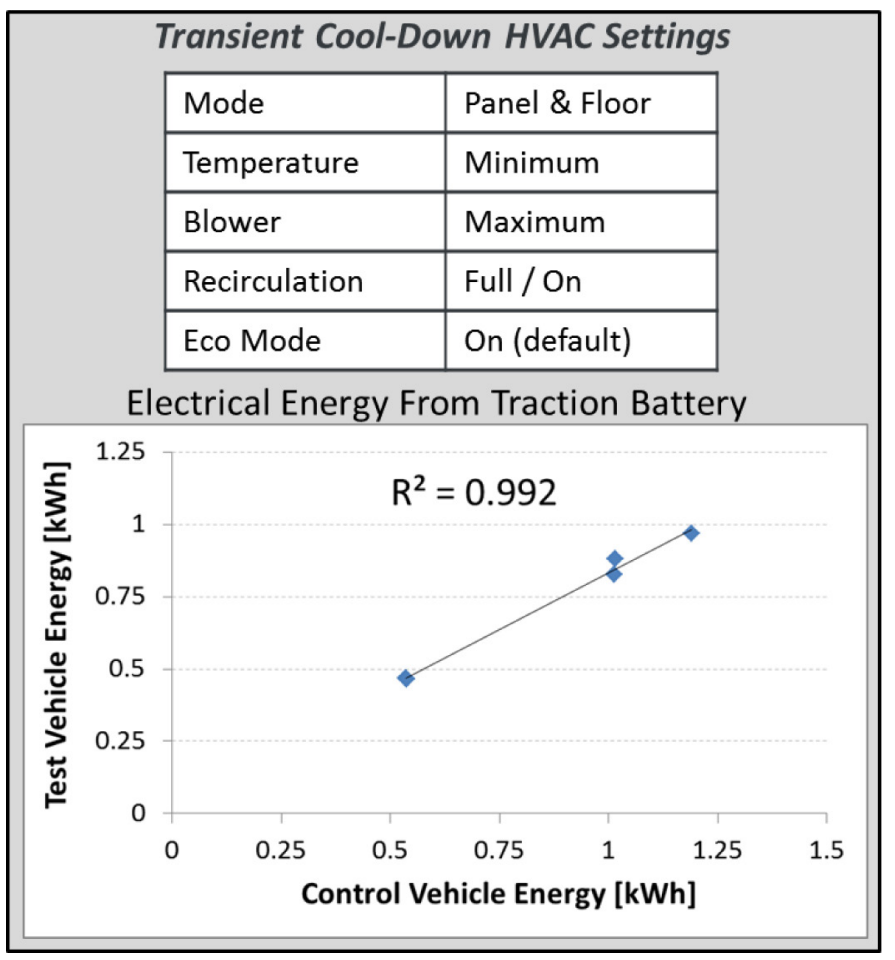

Figure 8A. Summary of transient warm weather baseline testing

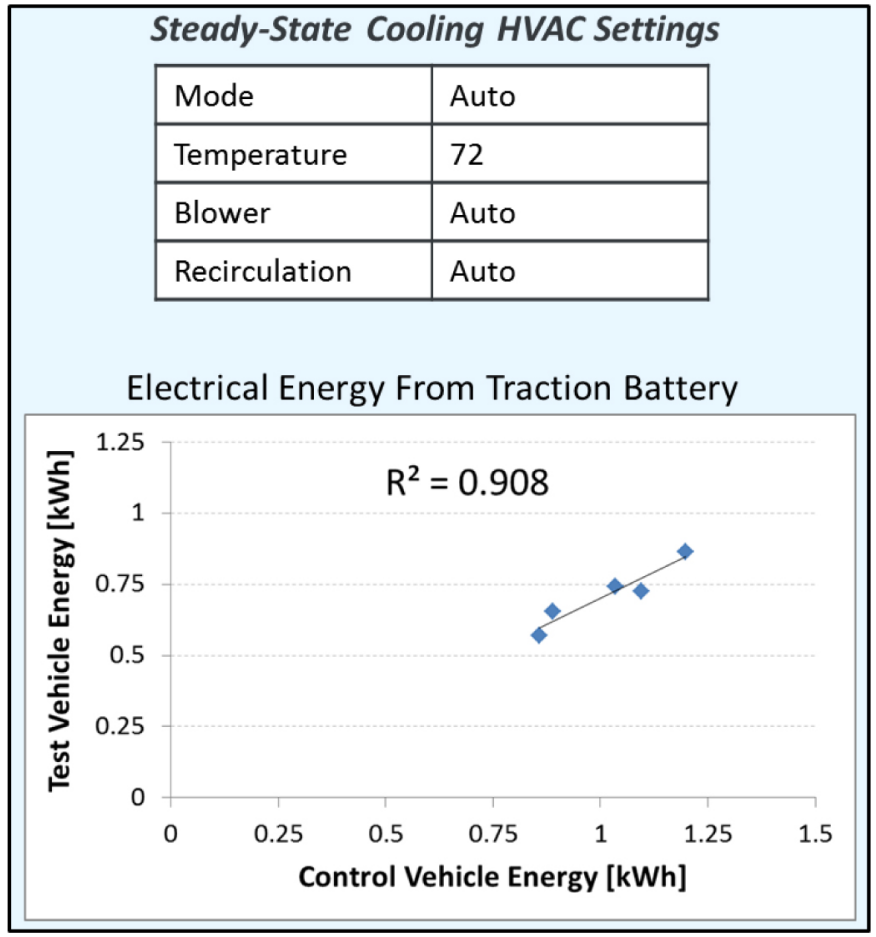

Figure 8B. Summary of steady-state warm weather baseline testing

The first summer technologies evaluated were three solar control glazing configurations, each of which provides a trade-off of properties while maintaining visible light transmission standards. The glass packages were provided by project partners PGW and Sekisui, and all packages consisted of the windshield and front and rear door glass. Plots of the transient and steady-state cooling energy use compared to the baseline are provided in Figure 9 . The results are the average of a minimum of three test days 
collected in good weather conditions. Vehicle energy delivered for climate control was normalized to the peak test day for the entire test season to remove seasonal and daily fluctuations. While normalizing results to the peak test day represents a maximum condition for Golden, Colorado, the climate is moderate in comparison to many regions of the United States. All glass packages provided benefits to both transient and steady-state cooling energy use, with particularly large benefits in the transient cool-down portion of the test. Package $\mathrm{C}$ provided the largest benefit, obtaining a $42.5 \%$ reduction in the transient phase and $12.8 \%$ reduction in the steady-state phase. For this reason, Package $\mathrm{C}$ will be included as part of the Phase II thermal load reduction system.

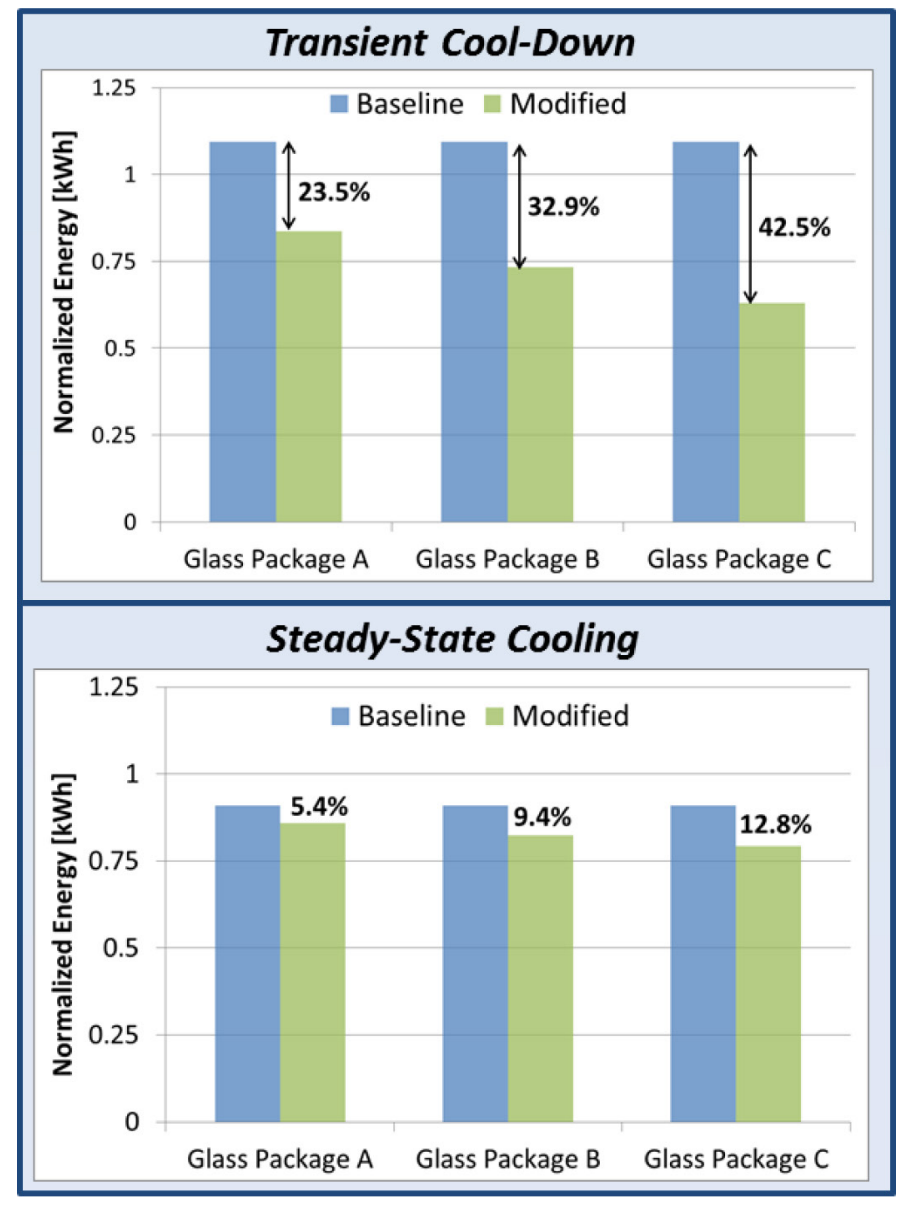

Figure 9. Transient and steady-state cooling energy used compared to baseline for glass packages $\mathrm{A}, \mathrm{B}$, and $\mathrm{C}$.

In addition to solar control glazings, the impact of solar reflective paint on warm weather cooling energy use was also quantified. Dark red solar reflective paint provided by PPG Industries was used for the tests and compared against the baseline color-matched standard version of the paint. Figure 6 shows the painted vehicles. Four tests were completed for the solar reflective paint configuration. The normalized average results compared to the baseline for both transient and steady-state cooling are provided in Figure 10. The solar reflective paint reduced transient cooling energy use by $5.3 \%$ and steady-state cooling energy use by $16.1 \%$. Due to the energy savings achieved for solar reflective paint, it will be included in the Phase II thermal load reduction package.

Ventilated/cooled seats were evaluated in warm weather conditions using the test method adapted to include occupants. The transient and steady-state results of warm weather testing using the ventilated/ cooled seats in comparison to baseline are provided in Figure 11. The ventilated/cooled seat had a significant impact on the energy required for the transient cool-down for two occupants, saving $25.2 \%$ with occupant C and $45.5 \%$ with occupant D. Due to poor weather conditions, the transient test data for occupants A and B were omitted from the results. The energy savings during the transient cool-down period were due to the reduced time necessary to achieve a target whole body sensation for the occupant. In addition to the savings for transient cool-down, the ventilated/cooled seats provided an energy savings during the steady-state portion of the test, ranging from a $10.3 \%$ to $17.2 \%$ reduction for cooling. During the steady-state portion of the test, energy savings were obtained by reducing the cooling for cabin air because the occupant was partially cooled with the ventilated/ cooled seat. Due to the energy savings obtained using the ventilated/ cooled seats for both the transient and steady-state cooling, the seats will be included in the Phase II thermal load reduction system.

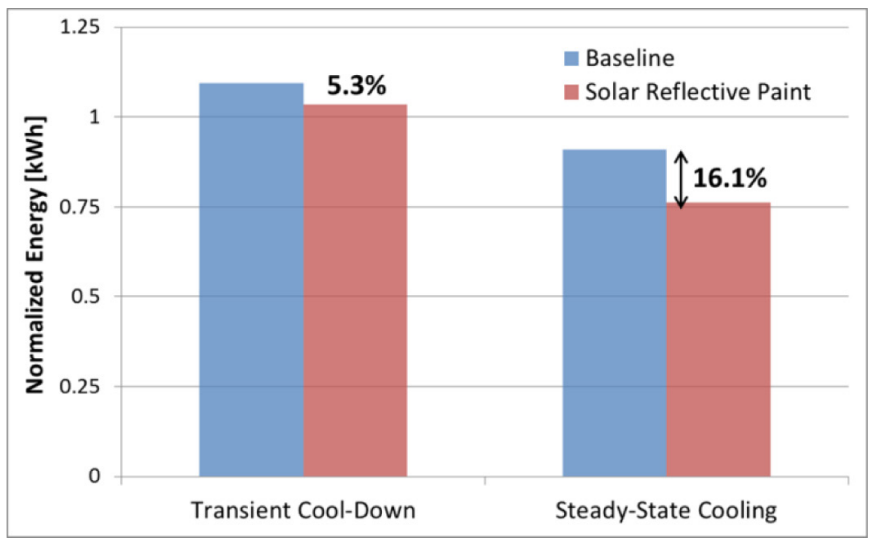

Figure 10. Transient and steady-state cooling energy use for vehicle modified with solar reflective paint compared to baseline

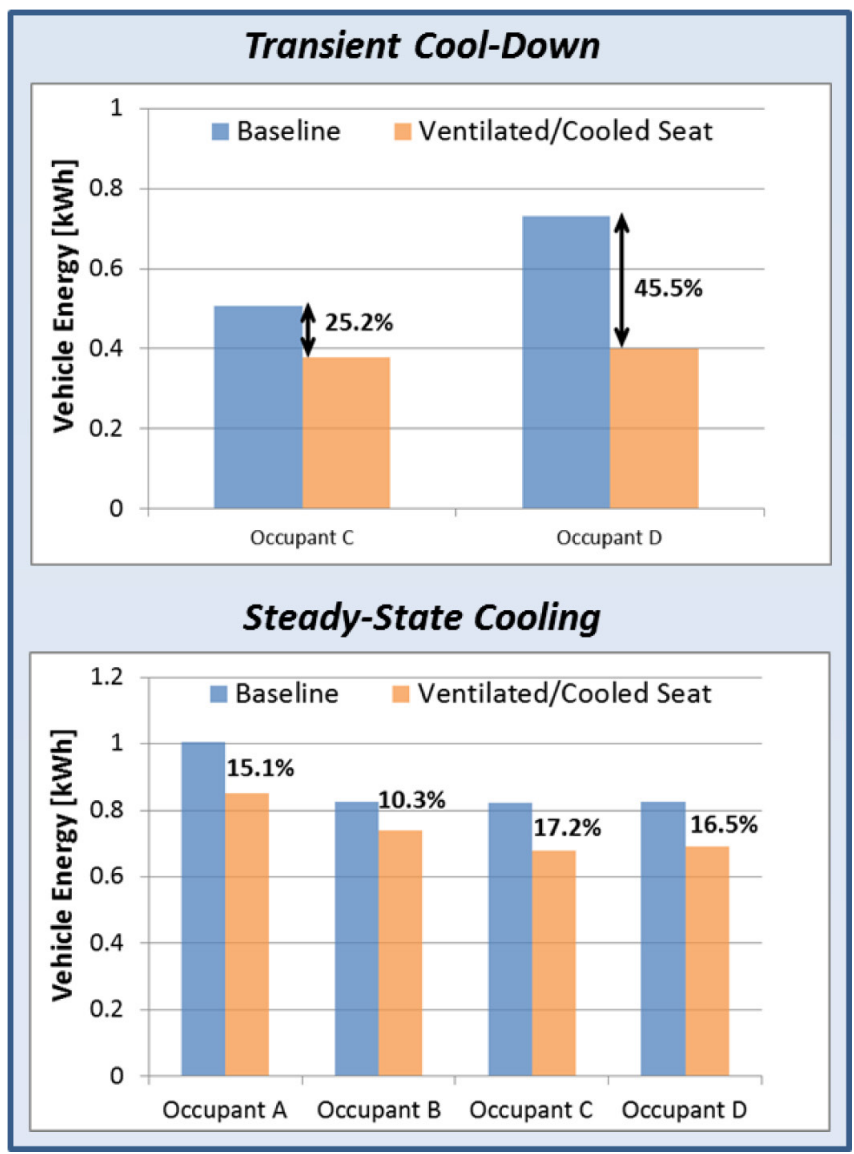

Figure 11. Transient and steady-state cooling tests using ventilated/cooled seats compared to baseline. Results are specific to each occupant. 


\section{Winter Technology Evaluations}

A summary of the cold weather baseline testing results is provided in Figure 12. For both transient warm-up and steady-state heating, the combined heater core and PTC electrical heater energy into the cabin between the two vehicles had a strong linear correlation with least-squares coefficients of determination $\left(\mathrm{R}^{2}\right)$ of 0.996 and 0.988 , respectively. The linear baseline correlation was used for calibrating the vehicles during technology performance evaluations.
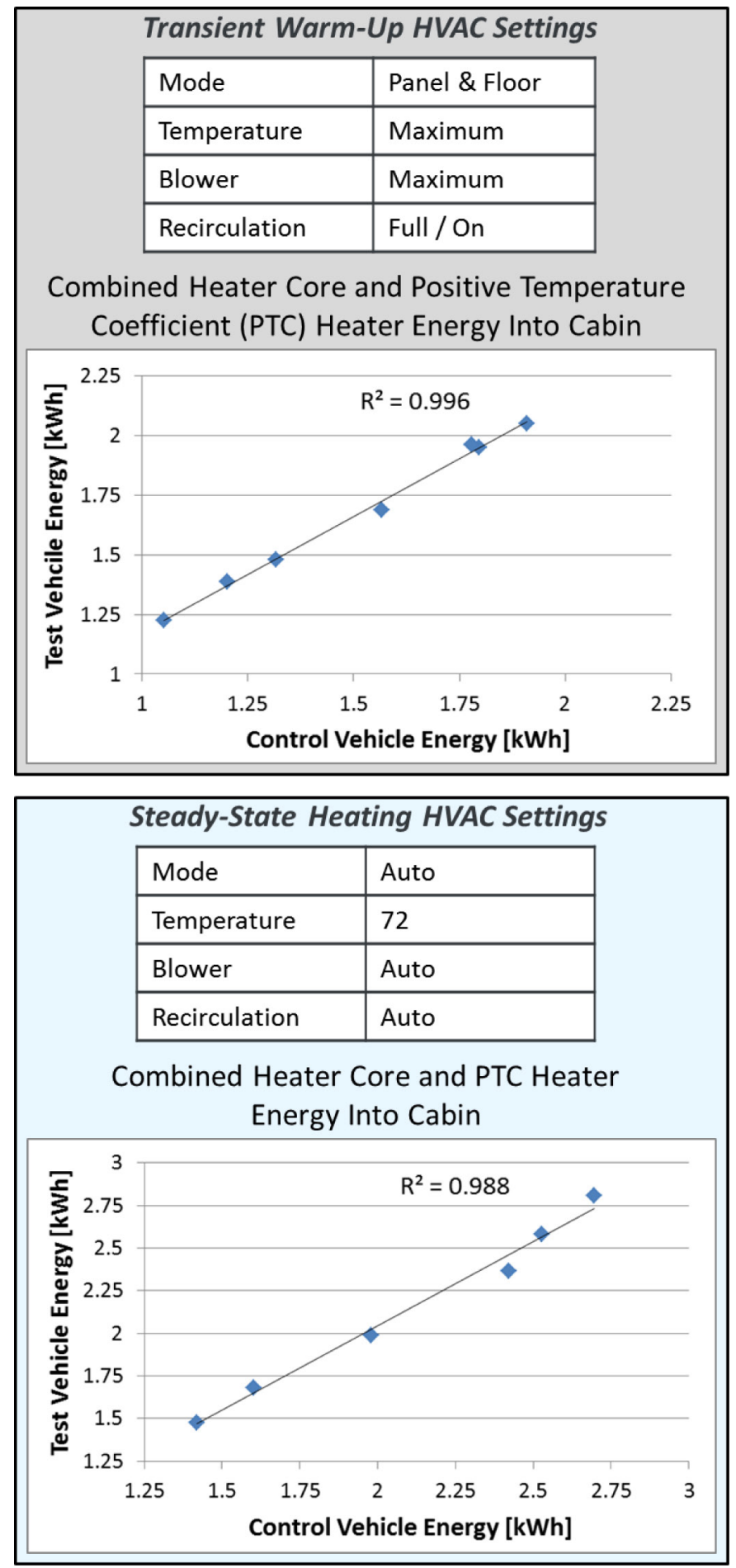

Figure 12. Summary of cold weather baseline testing

Next, a combination of contact and non-contact heated surfaces was tested. The results for transient and steady-state heating using heated surfaces are provided in Figure 13. Testing of the heated surfaces for three different occupants resulted in a $1 \%-2 \%$ increase in energy use for the transient warm-up period and a $29 \%-59 \%$ decrease in energy use for the steady-state heating period. The variation in energy savings obtained during the steady-state period is due to the subjective nature of engineering evaluations of thermal sensation. The minor penalty of heated surfaces on transient heating performance can be partially or completely eliminated when used in conjunction with grid-connected thermal preconditioning. Therefore, the benefits of heated surfaces are enabled by preconditioning and allow the vehicle to operate in the steady-state heating condition where large potential benefits are possible. For this reason, heated surfaces will be included in the full system package in Phase II.

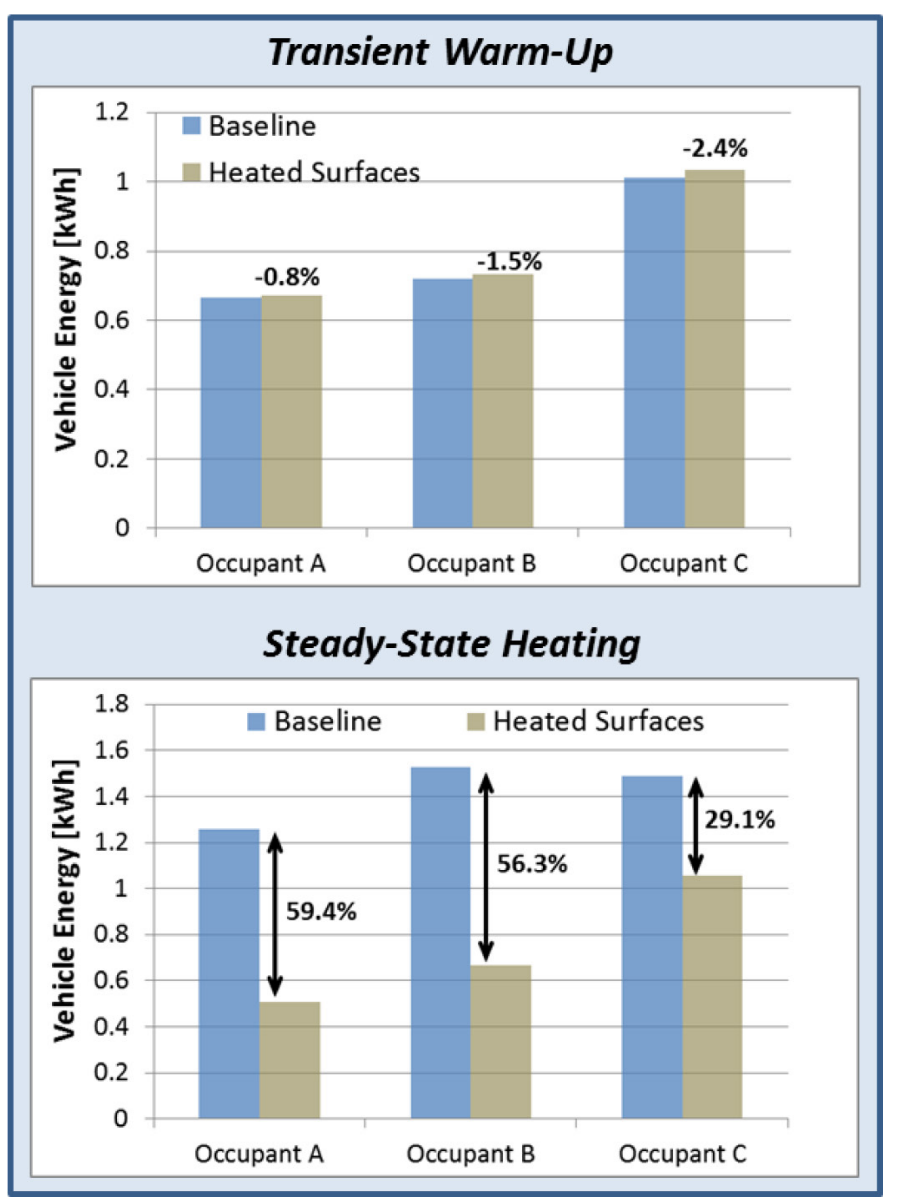

Figure 13. Transient and steady-state heating energy use for vehicle modified with heated surfaces compared to baseline

The final winter technology evaluation was defogging performance of heated windshield and door demisters compared to the baseline vehicle HVAC system defogging. The results for the time taken to clear the fogged windshield in addition to the average power needed for defogging compared to the baseline is provided in Figure 14 and represents an average of three tests. The heated windshield and door demister combination was able to clear the windshield in an average of 16.5 minutes compared to an average of 20.5 minutes for the baseline system, providing a $19.5 \%$ improvement in time to clear the windshield. During the tests, the heated windshield and door demister system was able to reduce energy consumption by $67.8 \%$. In addition, the combined system maintained a $24.5 \%$ reduction in energy consumption while delivering moderate heating to the occupant compared to the baseline. Due to the significant reductions in the time to clear the windshield and energy use, in addition to the ability of the 
system to decouple occupant heating and defogging tasks, the heated windshield and door demister technology will be included in the Phase II full system package.

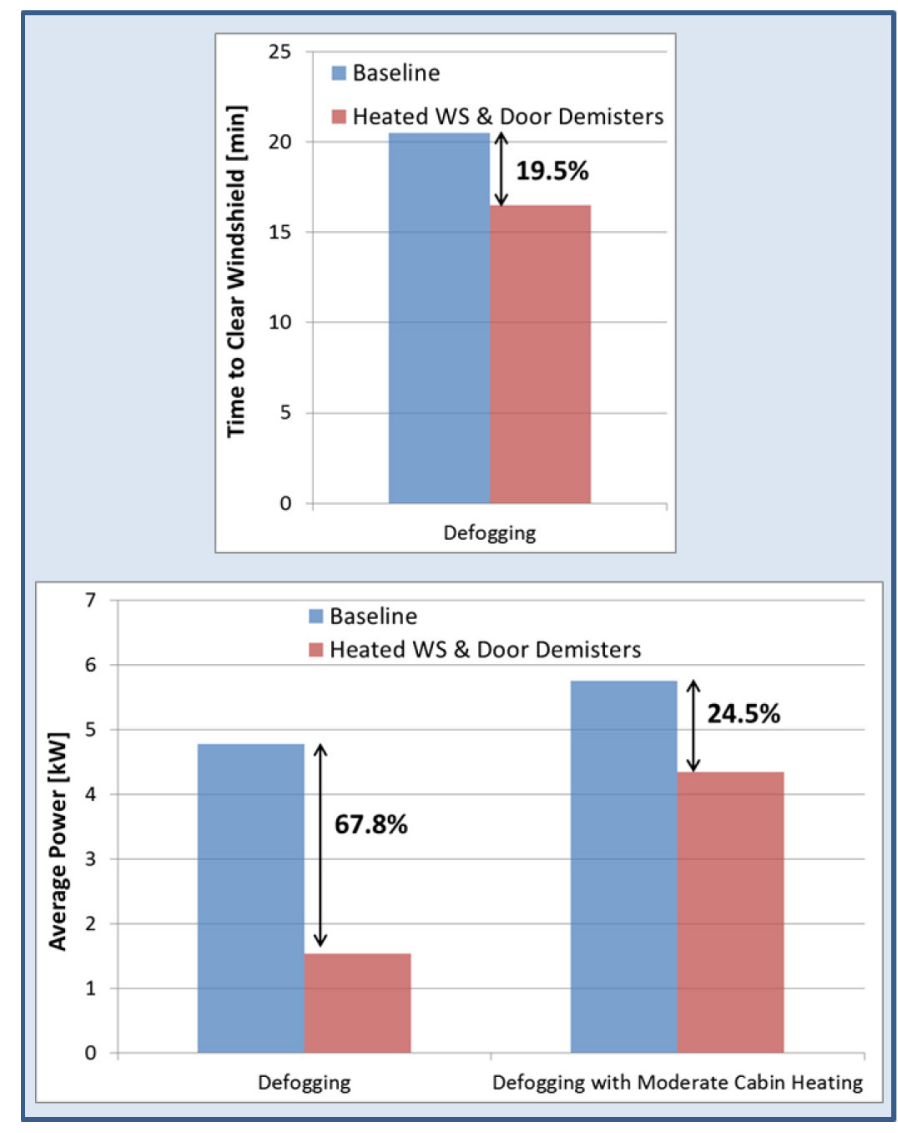

Figure 14. Cold weather defogging performance of heated windshield and door demisters compared to baseline

\section{Candidate Technology Go/No-Go Decision Matrix}

Data collected during both cold weather and warm weather Phase I testing were used as the primary method for completing the Phase I Go/No-Go decision matrix provided in Figure 15. Technologies that will be integrated into the Phase II complete thermal load reduction system are highlighted in green.

\begin{tabular}{|l|c|c|c|}
\hline Candidate Technology & $\begin{array}{c}\text { Transient } \\
\text { Improvement }\end{array}$ & $\begin{array}{c}\text { Steady-State } \\
\text { Improvement }\end{array}$ & $\begin{array}{c}\text { Go/No-Go for } \\
\text { Phase II }\end{array}$ \\
\hline Glass Package A & $24 \%$ & $5 \%$ & No-Go \\
\hline Glass Package B & $33 \%$ & $9 \%$ & No-Go \\
\hline Glass Package C & $43 \%$ & $13 \%$ & Go \\
\hline $\begin{array}{l}\text { Ventilated/Cooled } \\
\text { Seats }\end{array}$ & $\begin{array}{c}25 \text { to } 46 \% \\
\text { (occupant specific) }\end{array}$ & $\begin{array}{c}10 \text { to } 17 \% \\
\text { (occupant specific) }\end{array}$ & Go \\
\hline Solar Reflective Paint & $5 \%$ & $16 \%$ & Go \\
\hline Heated Surfaces & $\begin{array}{c}-1 \text { to }-2 \% \\
\text { (occupant specific) }\end{array}$ & $\begin{array}{c}29 \text { to } 59 \% \\
\text { (occupant specific) }\end{array}$ & Go \\
\hline $\begin{array}{l}\text { Heated Windshield \& } \\
\text { door demisters }\end{array}$ & $\begin{array}{c}20 \% \text { improvement in time-to-clear } \\
25-68 \% \text { estimated energy savings } \\
\text { dependent on cabin heating settings }\end{array}$ & Go \\
\hline
\end{tabular}

Figure 15. Candidate technology go/no-go decision matrix

\section{Summary/Conclusions}

Through collaboration between NREL and the project partners, Phase I individual thermal load reduction technologies were designed, manufactured, and evaluated. Two vehicles were instrumented for both cold and warm weather testing at NREL's test facility, and test methods were developed to capture the performance of all technologies. Three solar control glazings, solar reflective paint, and ventilated/cooled seats were evaluated in warm weather conditions. Heated surfaces, and a heated windshield combined with door demisters were evaluated in cold weather conditions. Glass package C, ventilated/cooled seats, solar reflective paint, heated surfaces, and heated windshield and door demisters were selected for Phase II integration. While glass packages A and B showed significant energy savings over the baseline for cooling, glass package $\mathrm{C}$ was selected as the top performer. The successful technologies will be integrated into a complete thermal load reduction system package in future work and the system performance evaluated compared to the baseline vehicle configuration.

\section{References}

1. Rask, E., “Argonne National Laboratory Advanced Powertrain Research Facility Data," Presentation at the Vehicle Systems Analysis Technical Team (VSATT) meeting, April 2, 2014.

2. Zhang, H., Arens, E., Huizenga, C., Han, T., "Thermal sensation and comfort models for non-uniform and transient environments, part III: Whole-body sensation and comfort," Building and Environment, 45 (2010), 399-410.

3. Jeffers, M., Chaney, L., and Rugh, J., "Climate Control Load Reduction Strategies for Electric Drive Vehicles in Warm Weather," SAE Technical Paper 2015-01-0355, 2015, doi: 10.4271/2015-01-0355.

4. Jeffers, M., and Rugh, J., "Electric Drive Vehicle Climate Control Load Reduction," presented at 2015 U.S. Department of Energy Vehicle Technologies Office Annual Merit Review, June 9, 2015, Arlington, VA.

5. Rugh, J., Chaney, L., Lustbader, J., and Meyer, J., "Reduction in Vehicle Temperatures and Fuel Use from Cabin Ventilation, Solar-Reflective Paint, and a New Solar-Reflective Glazing," SAE Technical Paper 2007-01-1194, 2007, doi:10.4271/2007$\underline{01-1194}$

6. Dieck, R.H., Steele, W.G., and Osolsobe, G., Test Uncertainty. ASME PTC 19.1-2005. New York, NY: American Society of Mechanical Engineers, 2005.

\section{Contact Information}

Cory Kreutzer

National Renewable Energy Laboratory

Transportation and Hydrogen Systems Center

Cory.Kreutzer@nrel.gov

303-275-3772 


\section{Acknowledgments}

This work was supported by the U.S. Department of Energy under Contract No. DE-AC36-08GO28308 with the National Renewable Energy Laboratory. Funding provided by the Vehicle Technologies Office, Office of Energy Efficiency and Renewable Energy, U.S. Department of Energy, for sponsoring this research. The authors would like to thank program managers David Anderson and Lee Slezak in the Vehicle Technologies Office.

The U.S. Government retains and the publisher, by accepting the article for publication, acknowledges that the U.S. Government retains a nonexclusive, paid-up, irrevocable, worldwide license to publish or reproduce the published form of this work, or allow others to do so, for U.S. Government purposes.

\section{Definitions/Abbreviations}

$\mathbf{A} / \mathbf{C}$ - air conditioning

EDV - electric drive vehicle

HATCI - Hyundai America Technical Center, Inc.

HVAC - heating, ventilating, and air conditioning

IR - infrared

NREL - National Renewable Energy Laboratory

PGW - Pittsburgh Glass Works

PHEV - plug-in hybrid electric vehicle

PTC - positive temperature coefficient

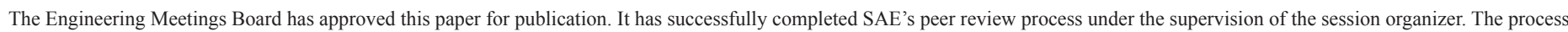
requires a minimum of three (3) reviews by industry experts.

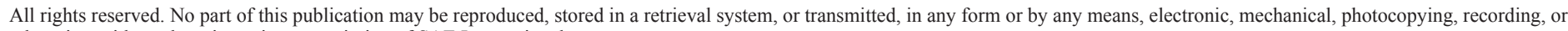
otherwise, without the prior written permission of SAE International.

Positions and opinions advanced in this paper are those of the author(s) and not necessarily those of SAE International. The author is solely responsible for the content of the paper.

ISSN 0148-7191

http://papers.sae.org/2017-01-0186 